\title{
Para um perfil do conhecimento gramatical da geração do milénio
}

\author{
Joana Batalha* \& Ana Luísa Costa** \\ *FCSH-UNL, CLUNL, **ESE-IPS, CLUL
}

\begin{abstract}
:
The academic year 2019/20 is marked by the arrival at university of students born in the new millennium. When this generation of students began to 'learn grammar' at school, teachers and other specialists were debating the terminology for basic and secondary education and the place of grammar in the curriculum was changing. In this article, we propose to contribute to a description of the knowledge about language to which millennials had access, more than a decade after the Terminological Dictionary (DT) became official (DGE, 2008). Assuming that there is a prescribed curriculum and a real curriculum, we start from the question what is the place of grammar in the curriculum to offer a comparative analysis of the discourse prescribed for the teaching of grammar in official curricular documents approved between 2000/01 and 2019/20. From this analysis, we present an empirical study assessing the grammatical knowledge in European Portuguese of 65 students entering higher education in 2019/20. For this study, we used a diagnostic instrument, assessing knowledge of different grammatical topics, mainly in the domains of morphology and syntax. The results obtained, which update data from previous studies on students' difficulties in grammar learning, suggest that terminological standardization and changes in the prescribed curriculum have not solved all the problems in the teaching of grammar.
\end{abstract}

Keywords: grammar teaching, grammar learning, grammatical knowledge, L1 curriculum, terminological dictionary

Palavras-chave: ensino da gramática, aprendizagens gramaticais, conhecimento gramatical, currículo de língua materna, dicionário terminológico

\section{Introdução}

O ano letivo 2019/20 é assinalado pela chegada ao ensino superior dos estudantes nascidos no novo milénio. Quando esta geração começou a "aprender gramática", professores e outros especialistas em ensino do Português discutiam publicamente a Terminologia Linguística para o Ensino Básico e Secundário (TLEBS) (DEB, 2002). Muitos dos materiais didáticos (manuais, fichas, testes intermédios), enquadrados pelos documentos orientadores em vigor, referiam a gramática como Funcionamento da Língua ou como Conhecimento Explícito. Neste artigo, propomo-nos contribuir para um perfil do conhecimento gramatical ${ }^{1}$ a que os millennials tiveram acesso, passada mais de uma década da oficialização do Dicionário Terminológico em Linha (DT) (DGE, 2008). Afinal, qual o lugar da gramática no currículo da primeira geração de estudantes do século XXI?

Partimos de um conceito abrangente de currículo, o qual, segundo Zabalza (2000, p. 25), pode ser encarado como uma "ideia aproximada, geral e integradora: currículo é todo o conjunto de ações

\footnotetext{
${ }^{1}$ Neste contexto, por "conhecimento gramatical" entende-se o conhecimento sobre a língua, ou o conhecimento explícito da língua, decorrente da "progressiva consciencialização e sistematização do conhecimento implícito no uso de língua" (Sim-Sim, Duarte \& Ferraz, 1997, p. 31). Nas Aprendizagens Essenciais (AE), "Gramática" designa a componente curricular que visa o desenvolvimento de uma "competência gramatical" (DGE, 2018).
} 
desenvolvidas pela escola no sentido de «oportunidades para a aprendizagem»". O nosso estudo estrutura-se em torno de dois polos desse continuum integrador, o currículo prescrito e o currículo real relativamente ao conhecimento escolarizado sobre a gramática da língua materna. Em distintas taxonomias sobre currículo, concebe-se um nível macro de tomada de decisão, a que está associado o conceito de "currículo prescrito" (Pacheco, 2001; Roldão, 1999) ou de intended curriculum (van den Akker, 2003), o qual corresponde ao currículo aberto, que expressa a visão e intenções políticas de um sistema educativo. Esta dimensão do currículo consubstancia-se, principalmente, nos programas e nos learning outcomes oficiais. O currículo prescrito para o ensino do Português como língua materna é um dos que tem sofrido mais alterações nas últimas duas décadas (Duarte, 2009; Rodrigues, 2017). Na secção 2, propomos uma análise do discurso do currículo prescrito para o ensino da gramática, considerando os documentos orientadores homologados entre 2000/01 e 2019/20. Saliente-se que o recorte de documentos estudados se circunscreve aos documentos em vigor durante o período de escolarização dos estudantes avaliados no estudo reportado na secção 3.

O currículo real corresponde a um conceito complexo, que não reúne consenso nos estudos sobre desenvolvimento curricular. Por um lado, pode ser associado ao nível das microdecisões tomadas em sala de aula, correspondendo ao que efetivamente acontece nas práticas, por oposição ao currículo prescrito (Roldão, 1999). Neste caso, o currículo real do ensino e da aprendizagem da gramática incluirá a forma como os professores interpretam os documentos curriculares, mediada pelas suas crenças e conceções sobre gramática, as opções didáticas que assumem, bem como as aprendizagens efetivas dos alunos. Outros autores, como van den Akker, Fasoglio \& Mulder (2008, p. 6), num estudo para o currículo de línguas do Conselho da Europa, propõem uma taxonomia tripartida de currículo, distinguindo do intended curriculum o implemented curriculum e o attained curriculum. Alusivos a processos de tomada de decisão pelo professor para e com as suas turmas, o implemented curriculum diz respeito às perceções dos docentes sobre o currículo e ao processo de ensino/aprendizagem (também designado currículo em ação), ao passo que o attained curriculum engloba as perceções dos alunos sobre as suas experiências de aprendizagem e, sobretudo, as aprendizagens que efetivamente alcançaram. $\mathrm{Na}$ secção 3, apresentamos um estudo empírico a partir do qual procuramos contribuir para uma descrição do perfil de conhecimento sobre a língua dos nascidos no novo milénio no ano em que chegam ao ensino superior.

\section{O lugar da gramática no currículo prescrito}

A análise comparativa das conceções associadas a "gramática" no discurso que estrutura os documentos orientadores do ensino do português constitui uma janela para o entendimento da visão e das intenções dominantes no sistema educativo, durante o período de escolarização da geração de estudantes que acaba de entrar no ensino superior. Se, segundo Roldão (1999, p. 23), o currículo prescrito constitui "o conjunto de aprendizagens que socialmente se pretende e se espera que a escola promova e garanta a todos os cidadãos", na presente secção focaremos a nossa atenção no conjunto de aprendizagens sobre a língua materna que se espera que os doze anos de escolaridade obrigatória tenham garantido a estes estudantes.

\subsection{Metodologia para a análise do discurso curricular}

O corpus inclui os documentos orientadores que estiveram em vigor durante os ciclos de ensino por que passaram os estudantes que, por norma, terão nascido em 2001 e entrado na escola em 2007/08. Como se apresenta na tabela 1, durante o percurso de escolaridade obrigatória da geração em estudo, estiveram em vigor quatro documentos para o ensino básico (do $1 .^{\circ}$ ao $3 .^{\circ}$ ciclo) e um nos três anos do ensino secundário. Para uma melhor compreensão da evolução de alguns conceitos no pensamento curricular para o ensino da língua materna, serão ainda tidas em conta as Aprendizagens Essenciais de Português (DGE, 2018), atualmente em vigor. Ainda que a publicação de cada um dos documentos curriculares tenha sido 
acompanhada de materiais de apoio à sua implementação e à formação de professores, também da responsabilidade do Ministério da Educação, excluímos desta análise estes documentos, por não integrarem, em sentido estrito, o currículo prescrito. Assim, incluem-se no corpus dois géneros de texto curricular, os programas, que traduzem uma "estrutura comum a uma cultura" e que, tipicamente, incluem objetivos, conteúdos, metodologias e avaliação (Zabalza, 2000) e os learning outcomes, que oferecem o perfil de saída das aprendizagens dos alunos.

\begin{tabular}{|c|c|c|c|}
\hline $\begin{array}{l}\text { CICLO DE ENSINO E } \\
\text { ANOS DE FREQUÊNCIA }\end{array}$ & DOCUMENTO ORIENTADOR & GÉNERO & EXTENSÃO \\
\hline \multirow{3}{*}{$\begin{array}{c}1 .^{\circ} \text { ciclo } \\
(2007 / 08-2010 / 11)\end{array}$} & $\begin{array}{l}\text { DGEBS (1991a). Programa de Língua Portuguesa - } \\
\text { plano de organização do ensino/aprendizagem - } \\
\text { ensino básico }-1 .{ }^{\circ} \text { Ciclo, vol. II. Lisboa: ME. DGEBS. }\end{array}$ & programa & [pp. 28] \\
\hline & $\begin{array}{l}\text { Sim-Sim, I., Duarte, I. \& Ferraz, M. J. (1997). A língua } \\
\text { materna na educação básica. }{ }^{2} \text { Lisboa: ME.DEB. }\end{array}$ & $\begin{array}{l}\text { learning } \\
\text { outcomes }\end{array}$ & [pp. 110] \\
\hline & $\begin{array}{l}\text { DEB (2001). Currículo nacional do ensino básico - } \\
\text { competências essenciais. Língua Portuguesa. Lisboa: } \\
\text { ME.DEB. }\end{array}$ & $\begin{array}{l}\text { learning } \\
\text { outcomes }\end{array}$ & [pp. 6] \\
\hline $\begin{array}{c}2 .^{\circ} \text { ciclo } \\
(2011 / 12-2012 / 13)\end{array}$ & \multirow{2}{*}{$\begin{array}{l}\text { Reis, C. (coord.), Dias, A. P., Cabral, A., Silva, E., } \\
\text { Viegas, F., Bastos, G., Mota, I., Pinto, M. \& Segura, J. } \\
\text { (2009). Programas de Português do ensino básico. } \\
\text { Lisboa: ME.DGIDC. }\end{array}$} & \multirow[t]{2}{*}{ programa } & \multirow[t]{2}{*}{ [pp. 175] } \\
\hline $\begin{array}{c}3 .^{\circ} \text { ciclo } \\
(2013 / 14-2015 / 16)\end{array}$ & & & \\
\hline $\begin{array}{c}\text { Secundário } \\
(2016 / 17-2018 / 19)\end{array}$ & $\begin{array}{l}\text { Buescu, H., Maia, L., Silva, M. G. \& Rocha, M. R. } \\
\text { (2014). Programa e metas curriculares de Português } \\
\text { do ensino secundário. Lisboa: ME. DGE. }\end{array}$ & $\begin{array}{l}\text { programa } \\
\mathrm{e} \\
\text { learning } \\
\text { outcomes }\end{array}$ & [pp. 56] \\
\hline
\end{tabular}

Tabela 1 - Documentos em vigor nos anos de frequência da escolaridade obrigatória do grupo em estudo

O estudo seguiu os procedimentos de uma "análise comparativa", à semelhança de outros estudos de documentos curriculares desenvolvidos para apoiar o desenho e implementação de novas políticas nos sistemas educativos. Esse é o caso do projeto Future for Education and Skills 2030, um estudo sobre currículos centrados em competências da $\mathrm{OCDE}^{3}$, e dos estudos sobre o currículo de Português, língua materna, de Duarte (2009) e Rodrigues (2017). Numa abordagem qualitativa/interpretativa, seguiu-se uma análise de conteúdo, considerando categorias previamente estabelecidas (Bardin, 1977, p. 119) a partir de conceitos da didática da gramática. Com o objetivo de caracterizar a Gramática, enquanto componente do currículo de Português, considerámos três categorias:

\footnotetext{
${ }^{2}$ A Língua Materna na Educação Básica. Competências nucleares e níveis de desempenho é um estudo referido como o documento orientador dos níveis de proficiência a alcançar nas aprendizagens de língua materna nos diferentes ciclos do ensino básico. Por essa razão, e seguindo o critério estabelecido em Duarte (2009), este estudo aparece incluído no nosso corpus.

${ }^{3}$ Projeto disponível em https://www.oecd.org/education/2030-project/curriculum-analysis/
} 
- o conceito de "gramática" e os objetivos do ensino da gramática, tendo em conta definições explícitas ou inferidas do discurso curricular, bem como designações que esta componente assumiu em diferentes textos;

- o espaço ocupado pela Gramática na sua relação com as restantes componentes curriculares, em concreto, com a Compreensão Oral, a Expressão Oral, a Leitura, a Escrita ou a Educação Literária;

- a natureza das estratégias de ensino, atendendo às orientações metodológicas veiculadas pelas orientações curriculares.

A forma como se conceptualiza cada uma destas categorias no discurso dos documentos orientadores que regularam o percurso de aprendizagem da gramática da geração do novo milénio é apresentada na próxima secção.

\subsection{Análise do discurso curricular sobre gramática}

Embora seja comum reconhecer que raramente existem efeitos imediatos entre inovações curriculares e mudança das práticas (Rodrigues, 2017; Roldão, 1999; van den Akker, 2003; Zabalza, 2000), em algumas dimensões do ensino-aprendizagem há atualizações regulares, pelo menos a nível da forma. Disso são exemplo materiais didáticos, como os manuais escolares, que procuram validação atualizando termos dos documentos orientadores, ou as provas e exames nacionais, enquadrados pela legislação em vigor. Os alunos que frequentaram a escolaridade obrigatória entre 2007 e 2019 aprenderam gramática através de materiais didáticos que transpuseram conceitos e designações nem sempre consensuais.

Quando os alunos estavam no $1 .^{\circ}$ ciclo, dois documentos orientadores apontavam para conceptualizações distintas do ensino da gramática. Em (1), transcrevemos uma definição retirada do programa então em vigor (DGEBS, 1991) e, em (2), a definição do Currículo Nacional. Competências Essenciais (CNEB) (DEB, 2001), coerente com a sua fundamentação em Sim-Sim, Duarte \& Ferraz (1997), como se pode ler em (3).

(1) Descobrir aspetos fundamentais da estrutura e do funcionamento da Língua, a partir de situações de uso. (DGEBS, 1991, p. 138, o sublinhado é nosso)

(2) Entende-se por conhecimento explícito o conhecimento refletido, explícito e sistematizado das unidades, regras e processos gramaticais da língua. Esta competência implica o desenvolvimento de processos metacognitivos quase sempre dependentes da instrução formal, e permite aos falantes o controlo das regras que usam e a seleção das estratégias mais adequadas à compreensão e expressão em cada situação de comunicação. (DEB, 2001, p. 32, o sublinhado é nosso)

(3) Por conhecimento explícito entende-se a progressiva consciencialização e sistematização do conhecimento implícito no uso da língua. (Sim-Sim, Duarte \& Ferraz, 1997, p. 30, o sublinhado é nosso)

Se, no programa de 1991, herdeiro do paradigma comunicativo, a descoberta do funcionamento da língua estava dependente de situações de aprendizagem decorrentes dos usos de língua, na Leitura, na Escrita e na Oralidade, a partir de 2001, com o CNEB, o Conhecimento Explícito passou a ser entendido como uma competência curricular autónoma, associada ao desenvolvimento de processos metacognitivos. $\mathrm{O}$ Conhecimento Explícito, enquanto componente do currículo de L1, não se limitou a fins instrumentais, mas constituiu um conhecimento reflexivo que radica no desenvolvimento do conhecimento implícito e da consciência linguística, potenciados pela escolarização. A conceptualização do conhecimento escolar sobre a língua materna como um processo de tomada de consciência progressiva da língua adquirida e usada espontaneamente, enunciada em Sim-Sim, Duarte \& Ferraz (1997), teve continuidade no discurso curricular do programa de 2009, como se pode constatar no objetivo definido para o Conhecimento Explícito da Língua no $2 .^{\circ}$ ciclo. 
(4) O trabalho que incide sobre o conhecimento explícito da língua tem um objetivo triplo:

i) O desenvolvimento da consciência linguística dos alunos, num trabalho de observação, comparação e manipulação de dados, para descoberta de regularidades no funcionamento da língua;

ii) A sistematização e a explicitação dessas regularidades, com recurso ou não à metalinguagem;

iii) A mobilização dos conhecimentos adquiridos na compreensão e na produção de textos orais e escritos. (Reis et al., 2009, p. 72)

Este triplo objetivo contempla, de forma equilibrada, a dimensão instrumental do ensino da gramática, mas destaca, como finalidades primeiras, o desenvolvimento da consciência linguística, suportado por um trabalho autónomo de manipulação de estruturas linguísticas, e a sistematização e explicitação de conhecimento sobre a língua, com ou sem recurso a termos gramaticais. A esta didática da gramática corresponde a definição em (5), do programa de 2009, que manifesta coerência conceptual com a definição do CNEB, transcrita em (2).

(5) Entende-se por conhecimento explícito da língua a reflectida capacidade para sistematizar unidades, regras e processos gramaticais do idioma, levando à identificação e à correcção do erro; o conhecimento explícito da língua assenta na instrução formal e implica o desenvolvimento de processos metacognitivos. (Reis et al., 2009, p. 16, o sublinhado é nosso)

Em contraste com esta visão curricular do conjunto de aprendizagens sobre a língua materna enquanto competência, radicada no desenvolvimento de capacidades reflexivas e de processos metacognitivos, no programa do ensino secundário (Buescu et al., 2014) que enquadrou o percurso de escolarização da primeira geração do milénio, o objetivo volta a ser dominantemente instrumental, como se pode verificar em (6).

(6) Desenvolver a consciência linguística e metalinguística, mobilizando-a para melhores desempenhos no uso da língua. (Buescu et al., 2014, p. 11, o sublinhado é nosso)

Além disso, neste programa, retomou-se a designação Gramática, associada a uma conceção tradicional do ensino e há muito desaparecida do currículo de Língua Portuguesa (Duarte, 2009; Rodrigues, 2017). Esta associação entre uma visão mais instrumental do ensino da gramática, tendo como finalidade o aperfeiçoamento dos usos de língua, típica do paradigma comunicativo dos anos 90, e uma visão normativa da gramática, persistente em muitas práticas de ensino, tem sido identificada no ensino da gramática de outros sistemas educativos (Costa, no prelo; Fontich \& García-Folgado, 2018; Rijt \& Coppen, 2017). A este propósito, van Rijt e Coppen (2017, p. 3) notam que o paradigma comunicativo veio reforçar "the already firm association between traditional grammar and prescriptivism". Também no caso português, os programas de português para o ensino básico (Buescu et al., 2015) e secundário (Buescu et al., 2014) reforçaram abordagens mais transmissivas, centradas no conhecimento de listas de termos e de conceitos, privilegiando um ensino da gramática em função da leitura e do aperfeiçoamento da expressão oral e escrita, como se pode confirmar em (7). 
(7) Os conteúdos e descritores de desempenho relativos à Gramática devem, pois, ser trabalhados na perspetiva de um adequado desenvolvimento da consciência linguística e metalinguística, de uma cabal compreensão dos textos e do uso competente da língua oral e escrita. (Buescu et al., 2014, p. 10, o sublinhado é nosso)

A par das oscilações de conceções sobre Gramática no discurso curricular, os alunos que frequentaram a escola nas primeiras décadas do milénio terão contactado com materiais didáticos (fichas, manuais, provas de aferição e exames) em que a designação atribuída a esta componente era variável. Na tabela 2, sistematizamos as designações em vigor entre 2007 e 2019.

\begin{tabular}{|c|c|c|c|}
\hline $\begin{array}{c}1 .^{\circ} \text { ciclo } \\
(2007 / 08-2010 / 11)\end{array}$ & $\begin{array}{c}2 .^{\circ} \text { ciclo } \\
(2011 / 12-2012 / 13)\end{array}$ & $\begin{array}{c}3 .^{\circ} \text { ciclo } \\
(2013 / 14-2015 / 16)\end{array}$ & $\begin{array}{c}\text { Secundário } \\
(2016 / 17-2018 / 19) \\
\end{array}$ \\
\hline $\begin{array}{l}\text { Funcionamento da } \\
\text { Língua - Análise e } \\
\text { Reflexão }\end{array}$ & \multirow{2}{*}{\multicolumn{2}{|c|}{ Conhecimento Explícito da Língua }} & \multirow[t]{2}{*}{ Gramática } \\
\hline Conhecimento Explícito & & & \\
\hline
\end{tabular}

Tabela 2 - Designações do conhecimento sobre a língua

Outra divergência presente no discurso curricular sobre ensino da gramática consiste no lugar ocupado por esta componente em relação aos outros domínios do currículo de língua materna, em concreto, a Compreensão Oral e a Expressão Oral, a Leitura e a Escrita. Nos programas da Reforma Educativa, a gramática ocupou um lugar na "periferia" (Duarte, 1991). Este facto é evidente na distribuição desequilibrada de pesos relativos a diferentes componentes do programa, segundo a qual a Oralidade, a Leitura e a Escrita tinham 25\% cada uma, ao passo que o Funcionamento da Língua dividia os seus $25 \%$ com o trabalho pedagógico de "programação" e "avaliação" (DGEBS, 1991b, p. 56). Por outro lado, por exemplo na estrutura textual do programa do $1 .^{\circ}$ ciclo, para todos os níveis, são identificados objetivos para a Comunicação Oral e para a Expressão Oral, enquanto para o bloco Funcionamento da Língua - Análise e Reflexão só se reconhecem objetivos de aprendizagem autónomos nos $3 .^{\circ}$ e $4 .^{\circ}$ anos. As aprendizagens formais sobre o funcionamento da língua são concebidas de forma integrada nas práticas discursivas, havendo uma conceção explícita de ensino da gramática como aprendizagem de conceitos a memorizar: "Não se espera que, durante este ciclo, os alunos venham a dominar a nomenclatura correspondente a todo o trabalho realizado. A consolidação desse trabalho de memorização será realizada ao longo do 2. ${ }^{\circ}$ ciclo do ensino Básico.” (DGEBS, 1991a, p. 157).

Num outro paradigma, no CNEB e no programa de 2009, o conhecimento sobre a língua encontra-se num lugar central do currículo de língua materna, no core curriculum (Duarte \& Costa, 2004). Como esclarecem Sim-Sim, Duarte \& Ferraz (1997), o Conhecimento Explícito da Língua é uma das cinco competências, a "que alimenta especificamente cada uma das quatro outras competências" (p. 12).

Erradicado o conceito de "competência" do currículo, com as orientações do programa de secundário (Buescu et al., 2014), a Gramática perdeu o seu lugar central, dividindo o espaço curricular com a Leitura, a Educação Literária, a Escrita e a Oralidade.

Os textos curriculares apresentam igualmente disparidades quanto a estratégias de ensino, ou seja, relativamente a "como ensinar gramática". De forma a conseguir comparabilidade entre metodologias, selecionámos, para um mesmo nível de ensino, um tópico comum do ensino da gramática. Sendo um dos 
conhecimentos gramaticais com maior destaque no estudo empírico sobre o perfil de conhecimentos gramaticais à entrada para o ensino superior (secção 3), comparámos as orientações sobre o ensino das funções sintáticas sujeito e predicado, alinhando, na tabela 3 , os processos de operacionalização e descritores de desempenho dos três programas do ensino básico.

Considerando os verbos de comando que descrevem a atividade do aluno, o grau de explicitação do conhecimento sobre as funções sintáticas sujeito e predicado varia consideravelmente. Numa perspetiva em que se assume que a instrução deve ser totalmente implícita, no programa de 1991, os alunos têm de distinguir elementos essenciais, manipulando as frases por expansão e por redução. Neste caso, não há necessidade de qualquer verbalização sobre as alterações experimentadas, nem de recorrer a metalinguagem.

\begin{tabular}{|c|c|c|}
\hline $\begin{array}{c}\text { Funcionamento da Língua - } \\
\text { Análise e Reflexão } \\
4^{\circ}{ }^{\circ} \text { ano } \\
\text { DGEBS (1991a, p. } 158)\end{array}$ & $\begin{array}{c}\text { Conhecimento Explícito da } \\
\text { Língua (CEL) } \\
3 .^{\circ} \text { e } 4 .^{\circ} \text { anos } \\
\text { Reis et al. }(2009, \text { p. } 57) \\
\end{array}$ & $\begin{array}{c}\text { Gramática } \\
\text { 4. }{ }^{\circ} \text { ano } \\
\text { Buescu et. al. }(2015, \text { p. } 63)\end{array}$ \\
\hline $\begin{array}{l}\text { Distinguir, em frases, os } \\
\text { elementos fundamentais (por } \\
\text { expansão e por redução). }\end{array}$ & $\begin{array}{l}\text { - Manipular palavras (ou grupos } \\
\text { de palavras) em frases: } \\
\text { - expandir, substituir, reduzir, } \\
\text { segmentar e deslocar elementos. } \\
\text { - Comparar dados e descobrir } \\
\text { regularidades: } \\
\text { - processos de concordância. } \\
\text { - Explicitar regras e } \\
\text { procedimentos: } \\
\text { - distinguir sujeito de predicado. } \\
\text { - Mobilizar o conhecimento } \\
\text { adquirido na compreensão e } \\
\text { expressão oral e escrita (2). } \\
\text { (2) Verificação experimental da } \\
\text { utilização dos sinais de pontuação } \\
\text { em articulação com as funções } \\
\text { sintácticas (ex. a não colocação da } \\
\text { vírgula entre o sujeito e o } \\
\text { predicado). }\end{array}$ & $\begin{array}{l}\text { Analisar e estruturar unidades } \\
\text { sintáticas. } \\
\text { 1. Identificar as seguintes funções } \\
\text { sintáticas: sujeito e predicado. }\end{array}$ \\
\hline
\end{tabular}

Tabela 3 - Estratégias para aprender gramática

No programa de 2009, a aprendizagem dos mesmos conteúdos envolve um processo que tem como ponto de partida procedimentos de manipulação sintática semelhantes: os alunos devem expandir, substituir, reduzir, segmentar e deslocar elementos nas frases. A condução da atividade metalinguística dos alunos, contudo, não fica por esta etapa. Num passo seguinte, são usados verbos de comando que remetem para a ativação de operações metacognitivas mais complexas, como comparar e descobrir regularidades em dados, envolvendo intencionalmente processos morfossintáticos como a concordância. $\mathrm{Na}$ etapa seguinte, a capacidade de distinguir sujeito de predicado implica a verbalização (com ou sem metalinguagem) de procedimentos, o que pode ser considerado um grau superior de conhecimento explícito da língua (Karmiloff-Smith, 1996). Este conhecimento, que vale por si, é, além do mais, potenciado pela sua 
mobilização em articulação com outras competências, como no caso da mestria intencional de regras de uso de vírgula, na competência de escrita (exemplo da "não colocação da vírgula entre o sujeito e o predicado").

Uma vez mais, o programa de 2015 contrasta com a abordagem anterior pela circunscrição de orientações pedagógicas a uma perspetiva transmissiva, segundo a qual o sujeito e o predicado são referidos como conteúdos declarativos, associados exclusivamente a um verbo de comando, o verbo identificar.

Além desta caracterização horizontal das abordagens metodológicas para o ensino do sujeito e do predicado, regressando ao percurso de aprendizagem em estudo, interessa conhecer a progressão de conhecimentos pressupostos quanto a estas funções sintáticas. A tabela 4 sistematiza as prescrições para o ensino do sujeito e do predicado ao longo dos doze anos de escolarização dos alunos do nosso estudo empírico.

\begin{tabular}{|c|c|c|c|}
\hline $\begin{array}{c}1 .^{\circ} \text { ciclo } \\
(2007 / 08-2010 / 11)\end{array}$ & $\begin{array}{c}2 .^{\circ} \text { ciclo } \\
(2011 / 12-2012 / 13)\end{array}$ & $\begin{array}{c}3 .^{\circ} \text { ciclo } \\
(2013 / 14-2015 / 16)\end{array}$ & $\begin{array}{c}\text { Secundário } \\
(2016 / 17-2018 / 19)\end{array}$ \\
\hline $\begin{array}{l}\text { Distinguir, em frases, os } \\
\text { elementos fundamentais } \\
\text { (por expansão e por } \\
\text { redução). } \\
\quad \text { (DGEBS, 1991a, p. 158) }\end{array}$ & 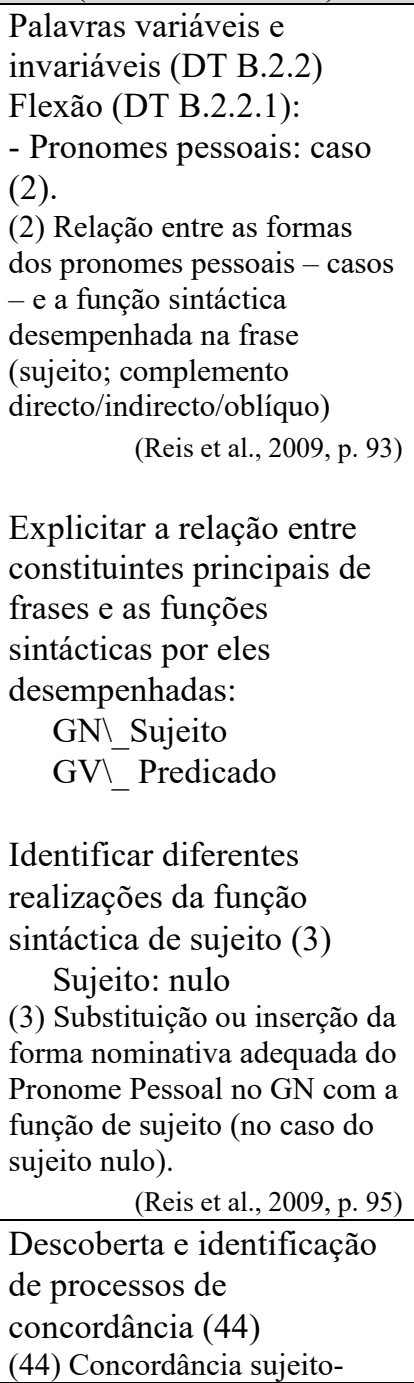 & $\begin{array}{l}\text { Sistematizar as } \\
\text { categorias relevantes } \\
\text { para a flexão das } \\
\text { classes de palavras } \\
\text { variáveis. } \\
\text { - Pronomes } \\
\text { pessoais: caso } \\
\text { nominativo, } \\
\text { acusativo, dativo e } \\
\text { oblíquo (2). } \\
\text { (2) Identificação da } \\
\text { relação existente entre } \\
\text { as formas dos } \\
\text { pronomes pessoais - } \\
\text { casos - e a função } \\
\text { sintáctica } \\
\text { desempenhada na frase } \\
\text { (sujeito; complemento } \\
\text { directo/indirecto) } \\
\text { (Reis et al., 2009, p. 130) } \\
\text { Detectar diferentes } \\
\text { configurações da } \\
\text { função sintáctica de } \\
\text { sujeito. } \\
\text { Sujeito frásico } \\
\text { Sujeito composto } \\
\text { (DT B.4.2.) } \\
\text { (Reis et al., 2009, p. 132) }\end{array}$ & $\begin{array}{l}\text { Funções sintáticas } \\
\text { a) retoma e } \\
\text { consolidação das } \\
\text { funções sintáticas } \\
\text { estudadas no Ensino } \\
\text { Básico, a saber: } \\
\text { sujeito, predicado, } \\
\text { vocativo, } \\
\text { complemento direto, } \\
\text { complemento } \\
\text { indireto, } \\
\text { complemento } \\
\text { oblíquo, predicativo } \\
\text { do sujeito, } \\
\text { complemento agente } \\
\text { da passiva, } \\
\text { modificador, } \\
\text { modificador do nome } \\
\text { (restritivo e } \\
\text { apositivo) } \\
\text { (Buescu et al., 2014, p. 16) }\end{array}$ \\
\hline
\end{tabular}




\begin{tabular}{|c|c|}
\hline $\begin{array}{l}\text { determinante) } \\
\text { (Sim-Sim, Duarte \& Ferraz, p. 77) } \\
\text { Descoberta e identificação } \\
\text { de funções sintácticas } \\
\text { centrais (30) } \\
\text { (30) Sujeito, predicado e } \\
\text { complemento de objeto } \\
\text { directo. } \\
\quad \text { (Sim-Sim, Duarte \& Ferraz, pp. } \\
\text { 85-86) }\end{array}$ & $\begin{array}{l}\text { verbo, nome-adjectivo, sujeito- } \\
\text { predicativo do sujeito. } \\
\text { (Sim-Sim, Duarte \& Ferraz, p. 90) }\end{array}$ \\
\hline
\end{tabular}

Tabela 4 - Aprendizagens sobre as funções sintáticas sujeito e predicado

Da leitura da tabela 4, destaca-se a progressão das aprendizagens prevista no ensino básico, em Sim-Sim, Duarte \& Ferraz (1997) e no programa de 2009, ancorada em capacidades (sistematizar relações, explicitar categorias) e conhecimentos (morfológicos e sintáticos) assentes numa descrição de complexidade crescente das funções sintáticas. Saliente-se ainda o facto de as aprendizagens sobre sujeito e predicado não serem trabalhadas de forma atomizada, mas na sua relação relevante com unidades e processos de interface de diferentes áreas do conhecimento linguístico, bem como na sua mobilização para outras competências. À semelhança do que foi anteriormente observado, o confronto com o programa de 2014, que enquadrou as aprendizagens da primeira geração do milénio no ensino secundário, torna evidente um menor investimento relativamente ao conhecimento gramatical. Para este ciclo de ensino, não se antecipa qualquer construção ou complexificação destas aprendizagens, indicando-se apenas a sua "retoma e consolidação".

Apesar das divergências conceptuais sobre ensino da gramática, que acabámos de destacar no discurso dos programas e learning outcomes, desde 2008 o ensino e as aprendizagens gramaticais são orientados pelo Dicionário Terminológico em Linha (DGE, 2008). A atualização coerente de termos e conceitos foi assumida por todos os documentos orientadores analisados, o que, como antes referimos, torna a geração de alunos que agora chega ao ensino superior a primeira geração a ter aprendido gramática, tendo por referência o DT, pelo menos, havendo falta de dados sobre as práticas de sala de aula, nas suas provas de aferição de $4 .^{\circ}$ e $6 .^{\circ}$ ano e nos exames de $9 .^{\circ}$ e de $12 .^{\circ}$ ano.

\section{O lugar da gramática no currículo real}

Com o debate em torno da uniformização terminológica e a preparação de novos programas de português no ensino básico, na primeira década do milénio, vários trabalhos contribuíram para o conhecimento sobre o currículo real da gramática tanto através do estudo de perceções e práticas dos professores (Sim-Sim \& Guimarães, 2006) como das aprendizagens dos alunos (Ucha, 2007; Costa, 2008). Relativamente à competência gramatical dos alunos em diferentes níveis de escolaridade, de um modo geral, concluiu-se nestes trabalhos que os alunos apresentavam lacunas graves na resolução de tarefas que exigiam conhecimento gramatical ou a sua explicitação, não dominando conceitos gramaticais básicos, mesmo à saída do ensino secundário (Costa, 2008). Vários fatores foram identificados como relevantes para este problema, entre eles a instabilidade terminológica e o lugar ocupado pela gramática no currículo prescrito.

Passada mais de uma década da oficialização do Dicionário Terminológico em Linha (DGE, 2008) e num momento em que a gramática tem lugar no currículo prescrito como competência nuclear em língua materna (DGE, 2018), propusemo-nos atualizar os dados disponíveis sobre as aprendizagens gramaticais dos alunos enquanto manifestação do "currículo alcançado". Para esta atualização, e procurando garantir alguma 
comparabilidade com dados já disponíveis, partimos de um dos estudos anteriormente realizados, o estudo de Costa (2008), aplicando a estudantes que chegaram ao ensino superior no ano letivo 2019/20 um instrumento de diagnóstico equivalente ao que foi usado naquele trabalho. Nas subsecções seguintes, apresentamos a metodologia e os resultados do estudo empírico realizado.

\subsection{Metodologia para o diagnóstico do conhecimento gramatical}

Para obtermos dados sobre o conhecimento gramatical de estudantes que completaram o seu percurso escolar nos primeiros anos do milénio, construímos um instrumento de recolha de dados, um teste de diagnóstico, equivalente ao que foi usado em Costa (2008) quanto aos tópicos de gramática testados e ao tipo de tarefas incluídas.

O teste encontra-se organizado em quatro tarefas, num total de 52 itens, que avaliam os seguintes tópicos: (i) classes de palavras, (ii) funções sintáticas, (iii) frases complexas e (iv) pontuação. Estas são aprendizagens gramaticais fundamentalmente do domínio da morfossintaxe, um dos domínios tradicionalmente mais ensinados e mais avaliados em provas de aferição e de exame. As tarefas requerem diferentes níveis de explicitação e uso de terminologia linguística.

Relativamente às classes de palavras, o teste inclui uma tarefa de identificação, dividida em dois grupos: no primeiro grupo, os estímulos linguísticos são dez frases que, duas a duas, apresentam formas fonética e graficamente iguais que pertencem a classes de palavras distintas, como exemplificado em (8) e (9) com um adjetivo e um advérbio; no segundo grupo, constituído por seis frases, pediu-se a identificação dos seguintes tempos e modos verbais: pretérito perfeito, imperfeito e mais que-perfeito composto do indicativo e presente, imperfeito e futuro do conjuntivo.

(8) O João é alto.

(9) A Maria fala alto.

A segunda tarefa avaliou a identificação de funções sintáticas principais em 20 frases: sujeito, predicado, complementos (direto, indireto e oblíquo) e predicativos (do sujeito e do complemento direto). Para algumas funções, foram testadas diferentes condições. Por exemplo, para o sujeito, incluíram-se sujeitos pré-verbais e pós-verbais e sujeitos nominais (simples ou com os nomes modificados por uma oração relativa) e frásicos (uma oração completiva). Os exemplos (10)-(13) apresentam os estímulos para a função de sujeito: (10) sujeito nominal pré-verbal, (11) sujeito nominal pós-verbal, (12) sujeito nominal pré-verbal com oração relativa e (13) sujeito frásico pós-verbal.

(10) As crianças beberam sumo de laranja.

(11) Ontem chegaram os meus primos.

(12) Os alunos que estudam muito conseguem bons resultados.

(13) Surpreende-me que a Maria tenha faltado à festa.

Para o predicado, incluíram-se predicados com um verbo copulativo, com um verbo transitivo (selecionando um complemento direto nominal ou frásico) e com um verbo intransitivo. Para o complemento direto, incluíram-se estímulos em que o complemento é nominal (simples ou em que o nome é modificado por uma oração relativa) e frásico (uma oração completiva), como exemplificado em (14)-(16).

(14) Os atletas cortaram a meta.

(15) O colecionador comprou o quadro que estava em leilão.

(16) A Luísa disse que vamos ao cinema amanhã. 
Com a terceira tarefa, avaliou-se o conhecimento gramatical sobre frases complexas formadas por coordenação e por subordinação, pedindo-se a classificação de orações. Os estímulos são 14 frases complexas com orações coordenadas (adversativa, conclusiva, explicativa) e com orações subordinadas (completivas finita e infinitiva, relativas com e sem antecedente, e adverbiais de diferentes subtipos semânticos). As frases (17)-(19) apresentam, a título de exemplo, alguns dos estímulos incluídos na tarefa, neste caso com orações relativas com antecedente (em (17) com valor restritivo e em (18) com valor explicativo) e sem antecedente (em (19)).

(17) O último livro que este autor escreveu foi premiado.

(18) O meu filho, que faz anos amanhã, trabalha na NASA.

(19) Quem estuda muito consegue bons resultados.

Por fim, incluiu-se no teste uma tarefa sobre erros de uso da vírgula tanto por ausência de uso de vírgula como por uso da vírgula em contextos não permitidos. Esta tarefa foi dividida em duas partes: primeiro, solicitou-se a identificação de três erros de uso de vírgula num texto dado; em seguida, pediu-se a explicitação de regras relacionadas com os três contextos identificados. Em (20), apresenta-se o texto usado nesta tarefa, com os três contextos de uso de vírgula assinalados: (i) vírgula não permitida após locução conjuncional; (ii) ausência de vírgula para delimitar constituinte intercalado; (iii) vírgula não permitida entre sujeito e predicado.

(20) A vespa asiática foi identificada pela primeira vez em território nacional no ano de 2011. Desde então, tem vindo a expandir-se para sul com prejuízos na produção de mel e na polinização, já que, (i) é predadora da abelha europeia. Nas últimas semanas, vespas velutinas, ou asiáticas, foram identificadas também na zona metropolitana de Lisboa. Depois de obrigar a encerrar os Jardins das Quintas das Conchas e dos Lilases, no Lumiar (ii) esta espécie, (iii) foi detetada na zona ocidental do Parque da Pena, em Sintra, que reabre esta quinta-feira depois de o ninho já ter sido injetado com inseticida. (texto adaptado de Joana Capucho, Vespa asiática alastra por todo o país, Diário de Notícias, 18/09/2019)

O instrumento construído foi administrado em suporte papel como teste de diagnóstico a 95 estudantes inscritos numa disciplina de introdução aos estudos linguísticos de primeiro ano de licenciatura, numa instituição de ensino superior portuguesa. Destes, 65 alunos cumpriram os critérios de participação para este estudo: estar inscrito pela primeira vez na unidade curricular, ser falante de Português Europeu língua materna, ter frequentado a escolaridade obrigatória em Portugal e ter preenchido e assinado a declaração de consentimento. A administração do teste teve a duração aproximada de 60 minutos.

Após a aplicação do instrumento, todas as respostas foram informatizadas e pontuadas como certas ou erradas. A análise dos dados foi feita quantitativamente a partir de medidas estatísticas descritivas.

\subsection{Análise dos resultados do diagnóstico do conhecimento gramatical}

Para a apresentação e discussão dos resultados, começaremos com resultados globais e apresentaremos, em seguida, os resultados de acordo com os domínios avaliados no teste, analisando cada uma das quatro tarefas.

No gráfico 1, representam-se as principais medidas de localização dos resultados do teste. Considerando a percentagem de acerto, a média é de $35 \%$ e a mediana de $31 \%$, sendo o valor mínimo de $3 \%$ e valor máximo de $78 \%$. Numa primeira leitura, estes valores apontam para desempenhos bastante baixos. Vejamos em que tarefas os alunos exibiram dificuldades. 


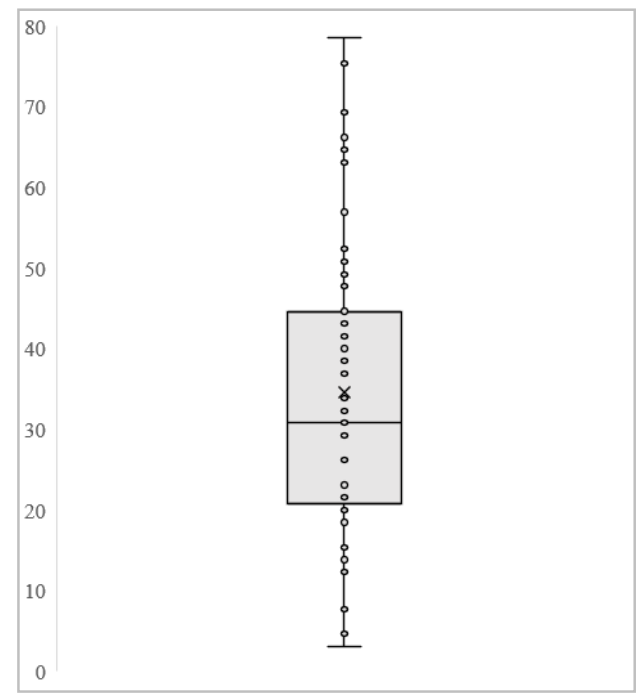

Gráfico 1 - Resultados globais

Na tarefa de identificação de classes palavras, a média da percentagem de acerto foi de $68 \%$. Uma análise dos resultados por classe de palavras (cf. gráfico 2) mostra que nem todas as classes colocaram o mesmo nível de dificuldade. As percentagens de acerto foram superiores (acima de 80\%) com nome, verbo e adjetivo e inferiores (abaixo de 50\%) com pronome, conjunção e advérbio, tendo sido esta última a classe que menos alunos identificaram corretamente. De notar que, à exceção do advérbio, os resultados são inferiores com classes funcionais, tal como constatou Costa (2008).

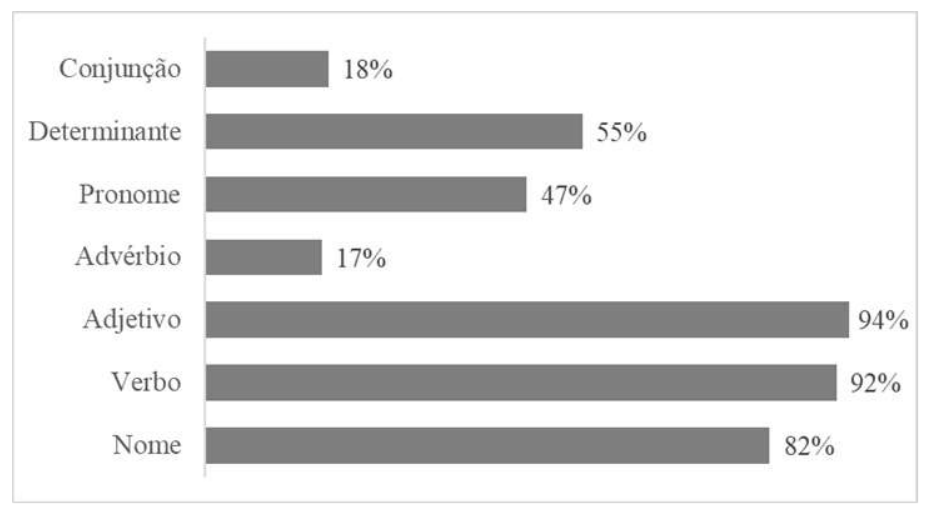

Gráfico 2 - Percentagem de acerto na tarefa de identificação de classes de palavras

Quanto aos tempos e modos verbais, a média da percentagem de acerto foi de apenas 19\%. Como é possível verificar no gráfico 3, nos itens que testaram o modo conjuntivo, os resultados apresentam taxas de acerto entre os $3 \%$ e os $22 \%$. No modo indicativo, estes valores são mais elevados; ainda assim, a 
percentagem de acerto mais alta é de 46\% com o Pretérito Perfeito. Poder-se-á concluir sobre estes resultados o que J. Costa conclui no seu estudo em 2008: assiste-se a "uma grande incapacidade [por parte dos alunos] de identificar formas verbais de acordo com a sua descrição morfológica, revelando desconhecimento dos paradigmas flexionais, sobretudo nos tempos do conjuntivo" (Costa, 2008, p. 153).

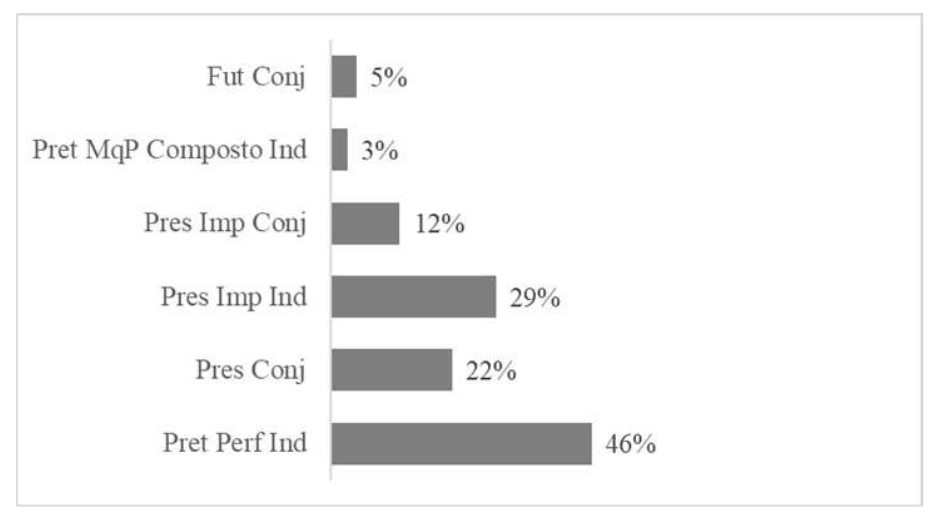

Gráfico 3 - Percentagem de acerto na tarefa de identificação de tempos e modos verbais

Relativamente às funções sintáticas, a média da percentagem de acerto foi de $46 \%$. Os resultados, apresentados no gráfico 4, situaram-se entre $16 \%$, na identificação de predicativo do complemento direto, e $65 \%$, na identificação de complemento indireto. Retomamos uma vez mais uma das conclusões de Costa (2008, p. 152), que se adequam a estes dados: “se a identificação do predicado não é [tão] problemática (...), os resultados apresentam-se bastante negativos quando se analisam as respostas dadas para a identificação de funções sintáticas menos frequentes, como o predicativo do sujeito e o predicativo do complemento direto".

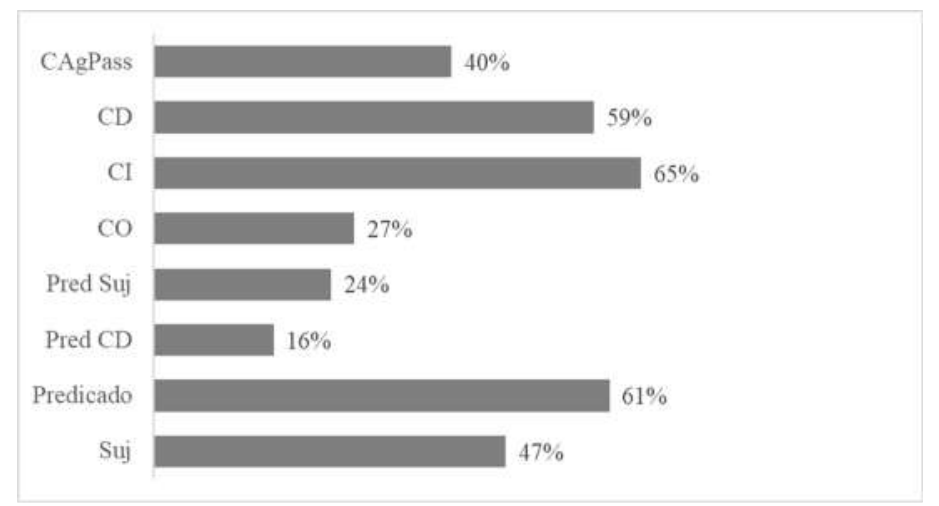

Gráfico 4 - Percentagem de acerto na tarefa de identificação de funções sintáticas

Importará salientar que, nos casos em que se testaram diferentes condições para a mesma função sintática, os resultados evidenciaram diferenças entre as condições. Isto foi particularmente evidente com a função sintática de sujeito, como se apresenta no gráfico 5. Na condição em que o sujeito é um GN simples 
em posição canónica, a percentagem de acerto é próxima de $90 \%$. Na mesma posição, mas na condição em que o sujeito integra um constituinte frásico, nomeadamente uma oração relativa, a percentagem de acerto é inferior, ainda que acima dos $50 \%$. A posição não canónica surge como um fator que gera dificuldades na identificação do sujeito, visto que as percentagens de acerto descem expressivamente nessas condições. Em particular, na condição em que se combina a natureza frásica do sujeito com a sua posição pós-verbal, apenas $8 \%$ dos alunos são capazes de identificar corretamente o sujeito. Mais uma vez, estes resultados vão ao encontro dos reportados por Costa (2008).

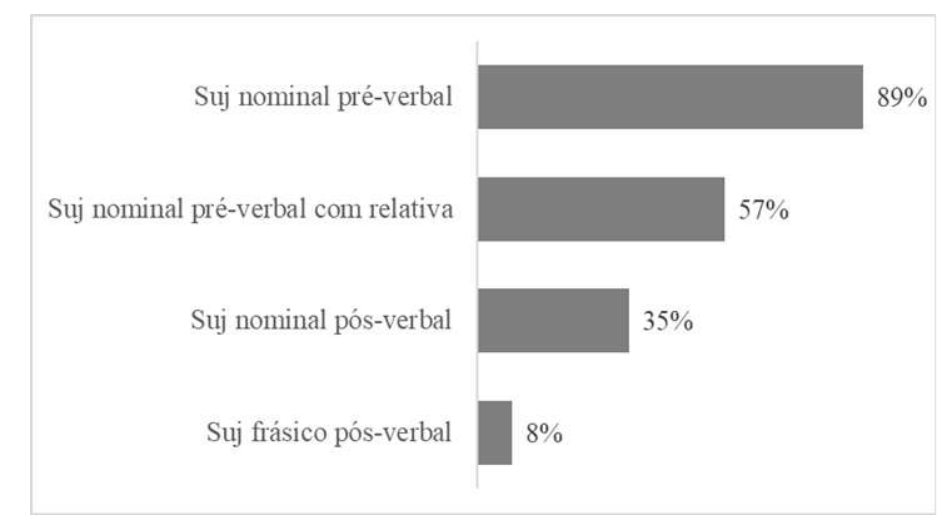

Gráfico 5 - Percentagem de acerto na tarefa de identificação de funções sintáticas (sujeito)

Na tarefa sobre frases complexas, a média da percentagem de acerto foi de $27 \%$, com valores aproximados para a coordenação $(25 \%)$ e para a subordinação $(28 \%)$. Uma vez que a maior parte dos itens incidia sobre orações subordinadas, apresentamos nos gráficos 6 e 7 os resultados para estas orações.

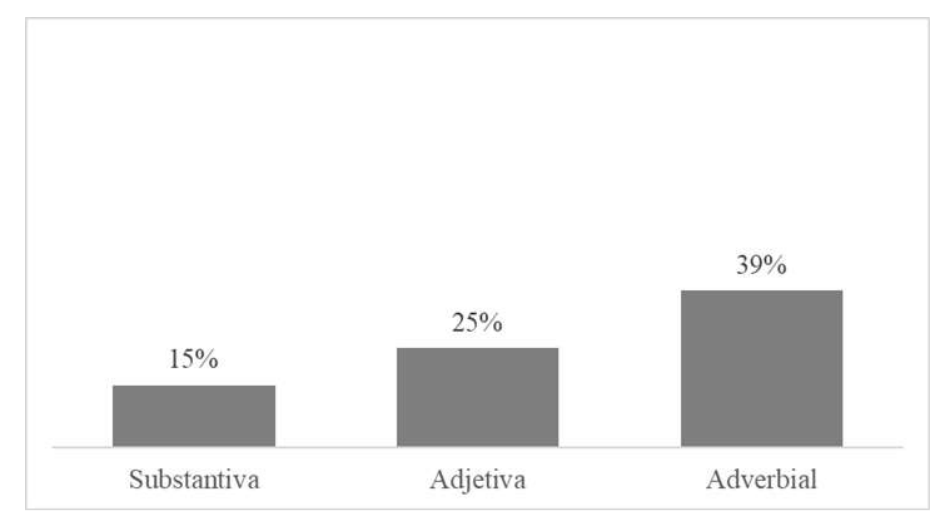

Gráfico 6 - Percentagem de acerto na tarefa de identificação de tipos de subordinadas

No gráfico 6, é possível observar os resultados de acordo com as três classes de subordinação distinguidas tradicionalmente. As subordinadas substantivas são aquelas que obtêm resultados mais baixos, sem diferenças entre subtipos de substantivas testados (completivas finita e infinitiva e relativa sem antecedente), seguidas pelas adjetivas, com valores iguais para relativas restritiva e explicativa. As adverbiais 
apresentam a percentagem de acerto mais elevada, próxima dos 40\%. Também no estudo de Costa (2008), apesar das dificuldades detetadas, de entre os três grupos de orações, as adverbiais foram as menos problemáticas para os alunos. No gráfico 7, que apresenta subtipos de orações adverbiais, observa-se que as condicionais e as temporais são as que uma maior percentagem de alunos consegue identificar corretamente. Ainda assim, a percentagem de acerto não ultrapassa os 50\%.

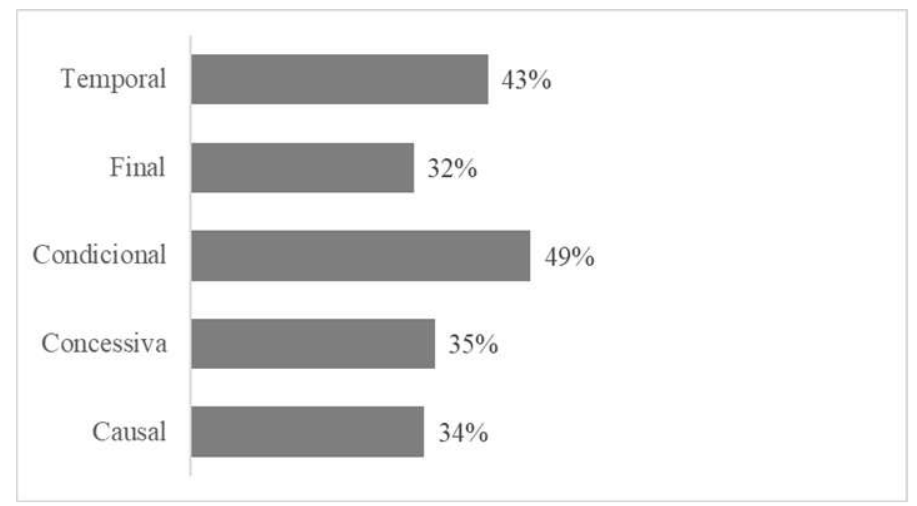

Gráfico 7 - Percentagem de acerto na tarefa de identificação de subtipos de adverbiais

Por fim, na tabela 5, apresentamos os resultados para a tarefa sobre uso da vírgula. Em relação à primeira parte da tarefa, dos três contextos testados, a identificação de uso não permitido da vírgula entre sujeito e predicado foi o contexto que obteve uma percentagem de acerto mais elevada. É também em relação a este contexto que a percentagem de acerto é maior na segunda parte da tarefa, que exigia a explicitação de uma regra de uso da vírgula associada ao contexto identificado. Contudo, esta percentagem é de apenas $15 \%$, o que significa que muito poucos alunos foram bem-sucedidos nesta última parte da tarefa. Nos restantes dois contextos, a percentagem de acerto pouco ultrapassa os 50\% na identificação e atinge valores de acerto muito baixos (de $6 \%$ e $2 \%$ ) na formulação de regras. Também nesta tarefa é possível estabelecer um paralelo com os resultados de Costa (2008). Apesar de o contexto com a conjunção ter obtido nesse estudo resultados superiores, os estudos convergem ao concluir sobre as dificuldades dos alunos na realização desta tarefa, especialmente quanto à sua incapacidade para explicitar uma regra de pontuação.

\begin{tabular}{|l|l|l|}
\hline & Identificar contexto & Formular regra \\
\hline (i) vírgula após locução conjuncional & $58 \%$ & $6 \%$ \\
\hline $\begin{array}{l}\text { (ii) ausência de vírgula para delimitação de constituinte } \\
\text { intercalado }\end{array}$ & $57 \%$ & $2 \%$ \\
\hline (iii) vírgula entre sujeito e predicado & $71 \%$ & $15 \%$ \\
\hline
\end{tabular}

Tabela 5 - Percentagem de acerto na tarefa de pontuação (vírgula)

De um modo geral, podemos afirmar que os resultados que acabámos de apresentar não demonstram uma melhoria evidente da competência gramatical da geração de alunos nascidos no novo milénio, ainda que, daquilo que é possível comparar com estudos anteriores, nomeadamente com o de Costa (2008), seja possível observar progressos em algumas das tarefas. Talvez possamos não identificar "dificuldades generalizadas", como em Costa (2008, p. 158), mas conseguimos identificar dificuldades persistentes. Ainda que os 
documentos orientadores desde 2001, com o CNEB, tenham consagrado um lugar para o ensino da gramática no currículo prescrito, os dados que conseguimos obter sobre o currículo real evidenciam que há problemas na sua aprendizagem que não estão ultrapassados.

\section{Considerações finais}

Qual é, afinal, o lugar da gramática no currículo da primeira geração de estudantes do século XXI? Esta foi a questão de partida para este estudo, com o qual nos propusemos contribuir para um perfil do conhecimento gramatical com que os primeiros alunos nascidos no novo milénio chegam ao ensino superior.

Da análise de aprendizagens gramaticais alcançadas pelos alunos, uma das dimensões do currículo real, as coincidências com os dados apresentados no estudo de Costa (2008) apontam para alguma estagnação no ensino da língua materna, havendo manutenção das dificuldades em tarefas que convoquem conhecimento linguístico explícito de estruturas de maior complexidade (como sujeitos frásicos, sujeitos que integrem relativas ou sujeitos em ordem não canónica) ou a verbalização e explicitação de regras que mobilizem conhecimento gramatical (como as regras de uso de vírgula). De salientar, contudo, que os tópicos que aparecem explicitamente descritos nos documentos orientadores (como complemento oblíquo, uma novidade do DT, ou o reconhecimento da vírgula entre o sujeito e o predicado) refletem resultados superiores a tópicos que não surgem expressos no discurso curricular, como sujeitos com formato frásico ou em ordem não canónica, ficando arbitrariamente dependentes das tomadas de decisão do professor.

O perfil delineado parece apontar para problemas que o currículo prescrito e a uniformização terminológica não resolveram. Em primeiro lugar, mantêm-se as hipóteses explicativas de Costa (2008): as dificuldades que permanecem podem decorrer do facto de a gramática não ser ensinada ou não ser ensinada de forma a possibilitar aprendizagens efetivas. Da análise do discurso curricular em vigor durante o percurso de escolarização dos alunos que responderam ao nosso questionário, constatámos a instabilidade das conceptualizações da Gramática, enquanto componente curricular, e a clivagem entre orientações no ensino básico e no ensino secundário em vigor nas primeiras décadas do milénio. Paralelamente, apesar da esperada estabilidade terminológica, as dificuldades persistentes com conceitos como o predicativo do complemento direto ou os paradigmas de flexão verbal devem suscitar curiosidade sobre o processo reflexivo (metalinguístico) acionado durante a aprendizagem dos conhecimentos gramaticais. Para isso, será necessário alargar a investigação ao processo reflexivo, não circunscrevendo o estudo da aprendizagem da gramática a respostas-produto de conhecimento.

A publicação, em 2018, das Aprendizagens Essenciais, coerentes entre os dois ciclos de ensino, faz mover o pêndulo curricular para o lugar atribuído ao conhecimento explícito, enquanto competência gramatical, em articulação com as outras competências, desde 2001. Mantendo a designação Gramática, os conceitos consignados nas AE retomam a perspetiva do CNEB. Ao longo do ensino básico, espera-se que o ensino da Gramática assegure "um adequado desenvolvimento da consciência linguística e um conhecimento explícito da estrutura, das regras e dos usos da língua portuguesa" (DGE, 2018a, p.2). No ensino secundário, "a aula de Português estará orientada para o desenvolvimento da (...) competência gramatical por meio de um conhecimento explícito sistematizado sobre aspetos essenciais dos diversos planos (fonológico, morfológico, das classes de palavras, sintático, semântico e textual-discursivo) da língua. (DGE, 2018b, p. 3). Em 2030, talvez outro estudo possa trazer um novo perfil de aprendizagens do conhecimento sobre a língua.

\section{Referências:}

Buescu, H., Maia, L., Silva, M. G. \& Rocha, M. R. (2014) Programa e metas curriculares de Português do ensino secundário. Lisboa: ME. DGE. 
Buescu, H., Morais, J., Rocha, M.R. \& Magalhães, V. (2015) Programa e metas curriculares de Português do ensino básico. Lisboa: ME. DGE.

Costa, A. L. (2020) Grammar Teaching 91-19: an analysis of the Portuguese curricula. Special Issue Research on L1 grammar in schooling: on the crossroads with many paths. L1 - Educational Studies in Language and Literature, 20, 1-31. https://doi.org/ 10.17239/L1ESLL-2020.20.03.03.

Costa, J. (2008) Conhecimento gramatical à saída do ensino secundário: estado atual e consequências na relação com leitura, escrita e oralidade In Reis, C. (org) Atas da Conferência Internacional de Ensino do Português. Lisboa: ME. DGIDC, pp. 149-165.

DEB (2001) Currículo nacional do ensino básico - competências essenciais. Língua Portuguesa. Lisboa: ME.DEB.

DGE (2008) Dicionário terminológico para consulta em linha (DT). http://dt.dge.mec.pt/

DGE (2018a) Aprendizagens essenciais do ensino básico. Retrieved from https://www.dge.mec.pt/aprendizagens-essenciais-ensino-basico

DGE (2018b) Aprendizagens essenciais - Ensino secundário. Retrieved from http://www.dge.mec.pt/aprendizagens-essenciais-ensino-secundario

DGEBS (1991a) Programa de Língua Portuguesa - plano de organização do ensino/aprendizagem - ensino básico $-1 .^{\circ}$ Ciclo, vol. II. Lisboa: ME. DGEBS.

DGEBS (1991b) Programa de Língua Portuguesa - plano de organização do ensino/aprendizagem - ensino básico - 3. ${ }^{\circ}$ Ciclo, vol. II. Lisboa: ME. DGEBS.

Reis, C. (coord.), Dias, A. P., Cabral, A., Silva, E., Viegas, F., Bastos, G., Mota, I., Pinto, M. \& Segura, J. (2009) Programas de Português do ensino básico. Lisboa: ME.DGIDC.

Duarte, I. (1991) Funcionamento da língua: a periferia dos NPP. In M. R. Delgado-Martins et al. Documentos do Encontro sobre os Novos Programas de Português. Lisboa: Colibri, pp. 45-59.

Duarte, I. \& Costa, A.L. (2004) The place of Portuguese as first language in the National Curriculum of Basic Education: Essential Competences. In M. Zabalza (Coord.) Flexibility in Curriculum. Citizenship and Communication. Lisboa: ME, pp. 323-330.

Duarte, R. (Coord.) (2009) Programas de Língua Portuguesa. Uma visão diacrónica. Lisboa: Direção Geral de Inovação e Desenvolvimento Curricular. Ministério da Educação.

Fontich, X., \& Garcia-Folgado, M. J. (2018) Grammar instruction in the Hispanic area: The case of Spain with attention to empirical studies on metalinguistic activity. Special issue Working on grammar at school in L1 education. Empirical research across linguistic regions. L1 - Educational Studies in Language and Literature, 18, pp. 1-39. Retrieved from https://doi.org/10.17239/L1ESLL-2018.18.04.03

Karmiloff-Smith, A. (1996) Beyond Modularity. A Developmental Perspective on Cognitive Science. Cambridge, Mass: MIT Press/Bradford Books.

Pacheco, J. A. (2001) Currículo: teoria e praxis. 2. ${ }^{\text {a }}$ ed. Porto: Porto Editora.

Rijt, J. van \& Coppen, P.-A. (2017) Bridging the gap between linguistic theory and L1 grammar education: experts' views on essential linguistic concepts. Language Awareness, 26(4), pp. 1-21. DOI: 10.1080/09658416.2017.1410552

Rodrigues, S. (2017) O ensino do português nas primeiras décadas do século XXI. Vol I. In A. Canelas et al. (Orgs.). Lei de Bases do Sistema Educativo. Balanço e Prospetiva. Vol. II, Lisboa: Conselho Nacional de Educação.

Roldão, M.C. (1999) Os professores e a gestão do currículo. Perspetivas e práticas em análise. Porto: Porto Editora.

Sim-Sim, I., Duarte, I. \& Ferraz, M. J. (1997) A Língua Materna na Educação Básica. Competências nucleares e niveis de desempenho. Lisboa: DEB.ME. 
Sim-Sim, I. \& Rodrigues, P. (2006) O ensino da gramática visto por professores e alunos. In I. Sim-Sim (coord.). Ler e ensinar a ler. Porto: Edições ASA, pp. 125-138.

van den Akker, J. (2003) Curriculum perspectives: An introduction. In J. van den Akker, W. Kuiper, \& U. Hameyer (Eds.). Curriculum landscapes and trends. Dordrecht: Kluwer Academic Publishers, pp. 1-10.

van den Akker, J., Fasoglio, D. \& Mulder, H. (2008) A curriculum perspective on plurilingual education. Preliminary study for the Guide for the development and implementation of curricula for plurilingual and intercultural education. Retrieved from https://rm.coe.int/16805a1e57 